\title{
EDITORIAL
}

\section{Revista Portuguesa de Psiquiatria e Saúde Mental: Obrigado Revisores Revista Portuguesa de Psiquiatria e Saúde Mental: Thank you Reviewers}

\author{
๑PEDRO CÂMARA PESTANA ${ }^{1,2^{*}}$, PPEDRO AFONSO ${ }^{1}$, ๑MARIA LUISA FIGUEIRA ${ }^{1,2}$ \\ ${ }^{1}$ Clínica Universitária de Psiquiatria e Psicologia Médica, Faculdade de Medicina da Universidade de Lisboa. Lisboa, Portugal. \\ ${ }^{2}$ Serviço de Psiquiatria e Saúde Mental, Centro Hospitalar Universitário Lisboa Norte
}

Palavraschave: Pandemia; Perturbações Mentais; Revisão por Pares; Saúde Mental

Keywords: Mental Disorders; Mental Health; Pandemics; Peer Review

Enquanto membros da equipa editorial fazemos um balanço muito positivo da atividade da Revista Portuguesa e Saúde Mental durante o ano de 2020. Entre 1 de janeiro e 31 de dezembro de 2020, recebemos 56 submissões através da plataforma eletrónica Open Journal Systems / Public Knowledge Project (OJS/PKP) e, ao longo de 3 números, foram publicados 19 artigos. Foram concluídos 28 processos de revisão por pares nesse período de tempo. O trabalho da equipa técnica e, em particular, dos revisores tem sido fundamental. No momento atual dispomos de 154 revisores registados na nossa plataforma, sendo que 52 destes se registaram no ano de 2020. Gostaríamos de destacar o esforço e expertise dos nossos revisores, sem os quais seria impossível manter o elevado padrão de rigor científico da nossa publicação e assim sustentar o seu progressivo crescimento. A todos os revisores, a Direção e o Conselho Redatorial da Revista Portuguesa de Psiquiatria e Saúde Mental, endereçam um sentido agradecimento.

É compromisso da Revista Portuguesa de Psiquiatria e Saúde Mental, com a ajuda dos nossos autores, alcançar a breve prazo a indexação nas principais bases de indexação internacionais". Nesse sentido, procurando melhorar a qualidade global da revista, procedeu-se a uma reconfiguração extensa não só das estruturas da revista, mas também a uma revisão das normas de publicação. Gostaríamos de destacar a criação do Conselho Redatorial composto por médicos psiquiatras com experiência em publicação científica, provenientes de diferentes geografias, e com áreas de interesse distintas.
Em março deste ano atribuímos a $1^{\mathrm{a}}$ Edição do Prémio de Melhor Artigo RPPSM 2020 ao artigo "Exposição a tempo de ecrã e psicopatologia na infância" "Os autores deste manuscrito serão distinguidos no XV Congresso Nacional de Psiquiatria, que terá lugar entre 17 e 20 de novembro, em formato virtual. Os autores terão ainda a oportunidade apresentar o seu trabalho para todos os participantes do Congresso.

Finalmente, o número que hoje publicamos reveste-se de particular interesse e atualidade, uma vez que aborda algumas temáticas importantes. No campo das intervenções biológicas, teremos um artigo de revisão sobre a experiência da utilização da lurasidona no tratamento da depressão bipolar e ainda um artigo original sobre a eficácia da eletroconvulsivoterapia de manutenção. Teremos também dois artigos relativos à COVID-19, um artigo original que abordará o impacto da pandemia nos internamentos psiquiátricos e uma carta ao editor refletindo sobre o uso da telepsiquiatria durante a COVID-19. Contaremos ainda com uma carta ao editor, em resposta ao artigo "Exposição a tempo de ecrã e psicopatologia na infância", ${ }^{1}$ pretende alargar a reflexão sobre este tema. Finalmente, teremos um interessante caso clínico sobre a síndrome de Gilles de La Tourette, destacando a importância de se conhecer bem esta entidade nosológica no sentido de se realizar um diagnóstico precoce.

Apresentamos abaixo uma lista correspondente aos revisores que procederam à revisão de artigos a pedido da

Recebido/Received: 2020-05-29

Aceite/Accepted: 2020-05-29

Publicado / Published: 2021-06-05

* Autor Correspondente/Corresponding Author: Pedro Câmara Pestana | Clínica Universitária de Psiquiatria e Psicologia Médica, Faculdade de Medicina da Universidade de Lisboa. Lisboa, Portugal | Av. Prof. Egas Moniz MB, 1649-028 Lisboa. Portugal | p.camarapestana@gmail.com

(C) Author(s) (or their employer(s)) 2020 and SPPSM Journal Re-use permitted under CC BY-NC. No commercial re-use. C Autor (es) (ou seu (s) empregador (es)) e Revista SPPSM2020. Reutilização permitida de acordo com CC BY-NC. Nenhuma reutilização comercial. 
Revista Portuguesa de Psiquiatria e Saúde Mental no ano de 2020, reiterando o nosso agradecimento.

Resta-nos apelar ao vosso apoio, submetendo os vossos trabalhos para publicação, de modo que possamos melhorar a qualidade da nossa revista. Fica, desde já, o nosso compromisso de prosseguirmos com o trabalho até aqui realizado no sentido de continuarmos a merecer a vossa confiança.

\section{Responsabilidades Éticas}

Conflitos de Interesses: Os autores declaram não ter nenhum conflito de interesses relativamente ao presente trabalho. Fontes de Financiamento: Não existiram fontes de financiamento ou bolsas para a realização deste trabalho.

Proveniência e Revisão por Pares: Comissionado; revisão editorial.

\section{Ethical Disclosures}

Conflicts of Interest: The authors have no conflicts of interest to declare.

Financing Support: This work has not received any contribution, grant or scholarship.

Provenance and Peer Review: Commissioned; editorial review.

\section{Referências}

1. Rafael A, Gouveia M, Guimarães-Fernandes S, Costa $\mathrm{AV}$, Melo S, Borges S, et al. Exposição a "Tempo de Ecrã" e Psicopatologia na Infância. Rev Port Psiquiatria Saúde Mental 2020;6:54-66. doi:10.51338/ rppsm.2020.v6.i2.161

\footnotetext{
A lista que se segue enumera os revisores que ao longo de 2020 procederam à avaliação de artigos a pedido da nossa revista

André Bonito Ferreira, Diogo Frasquilho Guerreiro, Fátima Ismail, Filipa Novais, Frederico Simões do Couto, Helena Donato, João Miguel Pereira, Joaquim Cereijeira, Licínia Ganança, Liliana Castro, Luis Madeira, Maria Luísa Figueira, Miguel Bajouco, Pedro Morgado, Ricardo Moreira, Rui Malta, Sofia Brissos, Sónia Ramos, Susana Almeida, Tiago Duarte, Vasco Nogueira.
} 